\title{
Hospitalized fall injuries and race in California
}

\author{
A A Ellis, R B Trent
}

\begin{abstract}
Objective-To compare risks for falls and their consequences among four major race/ethnic groups in California. Methods-Cases are 104902 hospital discharges of California residents with a same level fall injury as the principal external cause of injury. Included are all discharges for a first hospitalization for a given injury in any California non-federal hospital from 1995-97. Analysis includes crude and age standardized rates to describe risks, diagnoses, and consequences.
\end{abstract}

Results-Rates per 100000 for same level hospitalized fall injuries for whites (161) are distinctively higher than for blacks (64), Hispanics (43), and Asian/Pacific Islanders (35). Whites are more likely to have a fracture diagnosis and to be discharged to long term care rather than home, suggesting a poorer outcome or greater severity. Same level falls absorb a large proportion of hospital resources directed to the treatment of injuries.

Conclusions-In a four way comparison among race/ethnic groups, whites are distinguished by their high incidence, rates of fracture, and unfavorable discharge status. Prevention, particularly aimed at whites, has potential to improve health and save treatment resources.

(Injury Prevention 2001;7:316-320)

Keywords: falls; race

Falls are a major source of injury mortality and morbidity. In California in 1997, falls caused $7 \%$ of all injury deaths and, remarkably, $41 \%$ of all non-fatal injury hospitalizations. Falls have distinctive age and sex risk patterns. Unlike other common causes of injuries (traffic and violence, for example), fall rates climb steadily with age, reaching extremely high rates among the elderly. In these older groups, rates for women exceed those for men. These unusual age and sex patterns are well documented, both in the medical literature (which focuses mainly on osteoporosis and hip fractures) $)^{1-11}$ and in the epidemiologic literature. ${ }^{12-20}$

Falls also show race differentials unlike those of other injuries. In studies providing a comparison between whites and non-whites, whites appear to have higher rates of fall injuries. For example, in California, adult (age $20+$ ) hospitalization rates for non-fatal falls among whites were two to five times higher than for other races (unpublished data, in press). In a study of persons $65+$ years of age with fractures almost entirely from falls, white fracture rates were twice those of blacks. ${ }^{10}$ In another study of persons 65+ years, emergency medical transport rates for falls among whites were 1.4 times higher than for blacks. A predominately white population was also reported to have fall rates about twice those of Hawaiians of Japanese ancestry. ${ }^{1}$ A few researchers have studied falls among blacks ${ }^{21} 22$ and Mexican Americans (with no race/ ethnicity comparisons). ${ }^{23}$ One study of hip fractures went so far as to exclude non-whites and males to control for race/sex confounding because white females are the majority of the hip fractured clinical population. ${ }^{1}$ No studies have compared fall injury rates simultaneously among all the major race/ethnicity groups.

Race patterns for fall injuries appear to be large enough to warrant more detailed characterization than they have received thus far. In this report we take advantage of California's size and diversity to examine hospitalized fall patterns for whites, blacks, Hispanics, and Asian/Pacific Islanders, by age and sex. We describe race differences in the risk of hospitalized fall injuries and selected financial and medical consequences.

\section{Methods}

E CODED HOSPITAL DISCHARGE DATA

The California Office of Statewide Health Planning and Development (OSHPD) provided computerized hospital discharge summaries for 1995-97. All non-federal acute care hospitals in California are legally required to report discharges to OSHPD. Hospitals must report external cause of injury ( $\mathrm{E}$ codes) from the International Classification of Diseases, Ninth Edition, Clinical Modification (ICD-9-CM). Only first admissions for an injury are E coded. By selecting only E coded records, we selected incident cases and avoided duplication of cases readmitted or transferred. Hospital discharge data are generally reliable, as demonstrated by OSHPD's studies. To ensure quality data, OSHPD performs both computerized edits and analyst reviews on every discharge record.

\section{CASE DEFINITION}

This California-wide study includes only falls from slipping, tripping, or stumbling on the same level (E885) among residents of all ages requiring hospitalization in 1995-97. This (E885) is the most common type of fall, accounting for $32 \%$ in people $20-54$ years and $43 \%$ in those 55 years and older. As we have previously shown that fall risk factors and consequences differ by type of fall (unpublished data, in press), we did not aggregate different types of falls.

Study cases, therefore, consist of all first admissions of California residents where the principal external cause of injury is a same level 


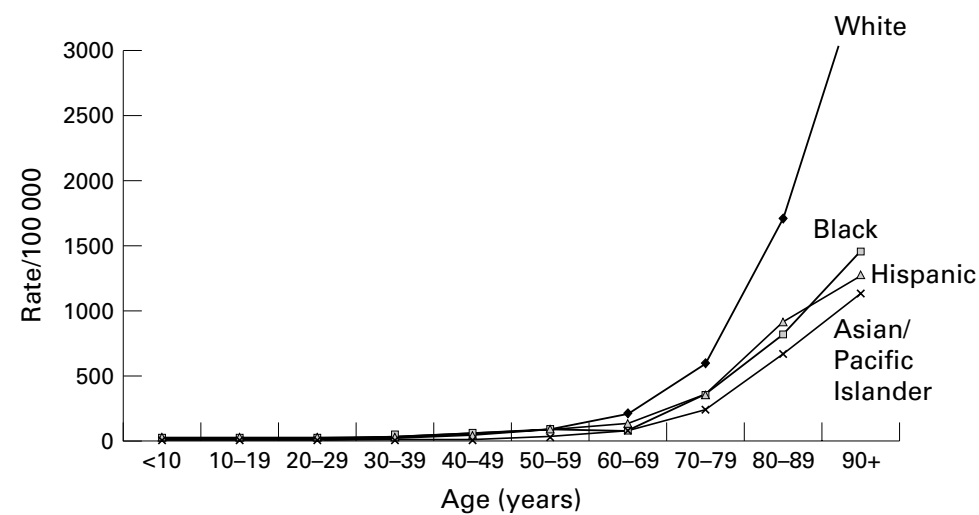

Figure 1 Annualized injury hospitalization rate (per 100 000) for same level falls by racelethnicity, California residents, 1995-97.

fall (E885). We examined data for three years combined (1995-97) to increase the number of cases and permit a detailed examination of all major race/ethnicity groups.

ANALYSIS

To determine risk, we calculated average race/ethnicity crude incidence rates per 100000 California population per year $($ rate $=$ mean falls for 1995-97/California population, 1 July $1996 \times 100000)$. Non-overlapping confidence intervals (CI) define statistical significance at the $95 \%$ level. California population estimates for 1996, provided by the California Department of Finance, include white, black, Hispanic, Asian, and Native American, a small category ( $n=162$ same level falls for 1995-97) not included in our analyses. Among Californians age 55 years and older, age composition varies by race/ethnic group. For example, the proportion of white females age $85+(2.7 \%)$ was 2.5 to 4 times greater than in the other race/ethnicity categories. Because age is strongly associated with fall incidence, compositional difference could make white women spuriously appear to be at greater risk. Rate comparisons are either shown as age specific rates or are directly standardized to the year 2000 standard million established by the National Center for Health Statistics. ${ }^{24}$

Costs include only hospital charges for first admission (excluding professional fees, which are not included in the discharge dataset) and thus underestimate total medical costs (which would include the costs of pre-hospital care, professional fees, and treatments after the first acute care discharge).

Fractures, particularly in seniors, are often associated with osteoporosis, prompting us to look for osteoporosis diagnoses. Only $8.3 \%$ of our fall cases 55 years or older had osteoporosis listed as a comorbidity on the discharge record. Other studies suggest this prevalence is low. ${ }^{25-28}$ Therefore, we did not try to determine whether osteoporosis could account for race differentials in hospitalized fall injuries.

\section{Results}

SEX, RACE, AND AGE

A total of 104902 residents of California suffered serious falls on the same level ("same level falls," hereafter) requiring hospitalization, an average rate of 108 per 100000 . These same level falls were the leading hospitalized injury, accounting for $16 \%$ of all hospitalized injuries during the study period. Although this study does not examine trends, same level fall injuries increased significantly over the study period:

- 1995-32 928 falls, rate 103 (95\% CI 102 to 104$)$

- 1996-35 123 falls, rate 109 (95\% CI 107 to 110 )

- 1997-36 851 falls, rate 112 (95\% CI 111 to 113$)$

Table 1 shows detailed age-sex-race patterns. The major findings are: (1) in all race groups, rates increased rapidly after age 50-59; (2) the

Table 1 Annualized injury hospitalization rates (per 100 000) for same level falls by racelethnicity, sex, and age, California residents, $1995-97$

\begin{tabular}{|c|c|c|c|c|c|c|c|c|c|c|c|c|}
\hline & \multicolumn{2}{|l|}{ Total $^{\star}$} & \multicolumn{2}{|l|}{ Male } & \multicolumn{2}{|l|}{ Female } & \multicolumn{2}{|l|}{ Total } & \multicolumn{2}{|l|}{ Male } & \multicolumn{2}{|c|}{ Female } \\
\hline & No & Rate & No & Rate & No & Rate & No & Rate & No & Rate & No & Rate \\
\hline & \multicolumn{6}{|c|}{ White } & \multicolumn{6}{|c|}{ Black } \\
\hline All ages & 82789 & 161 & 23944 & 94 & 58844 & 227 & 4350 & 64 & 1728 & 51 & 2622 & 76 \\
\hline$<10$ & 895 & 14 & 539 & 16 & 356 & 11 & 179 & 14 & 109 & 17 & 70 & 11 \\
\hline $10-19$ & 1567 & 26 & 1098 & 36 & 469 & 16 & 233 & 22 & 150 & 28 & 83 & 16 \\
\hline $20-29$ & 1388 & 22 & 760 & 23 & 628 & 21 & 199 & 18 & 111 & 19 & 88 & 17 \\
\hline $30-39$ & 2529 & 28 & 1286 & 28 & 1243 & 28 & 418 & 34 & 240 & 40 & 178 & 29 \\
\hline $40-49$ & 3802 & 45 & 1695 & 40 & 2107 & 51 & 515 & 55 & 256 & 57 & 259 & 53 \\
\hline $50-59$ & 4691 & 84 & 1691 & 61 & 3000 & 107 & 443 & 80 & 195 & 75 & 248 & 85 \\
\hline $60-69$ & 8292 & 197 & 2610 & 129 & 5682 & 259 & 254 & 69 & 175 & 105 & 343 & 170 \\
\hline $70-79$ & 21155 & 580 & 5654 & 361 & 15501 & 745 & 828 & 344 & 275 & 285 & 553 & 384 \\
\hline $80-89$ & 28677 & 1723 & 6783 & 1161 & 21893 & 2026 & 763 & 825 & 173 & 568 & 590 & 951 \\
\hline \multirow[t]{2}{*}{$90+$} & 9793 & 3556 & 1828 & 2816 & 7965 & 3784 & 245 & 1460 & 44 & 965 & 210 & 1718 \\
\hline & \multicolumn{6}{|c|}{ Hispanic } & \multicolumn{6}{|c|}{ Asian/Pacific Islander } \\
\hline All ages & 12143 & 43 & 5013 & 35 & 7130 & 53 & 3599 & 35 & 1236 & 24 & 2363 & 45 \\
\hline$<10$ & 1193 & 17 & 727 & 21 & 466 & 14 & 135 & 8 & 84 & 9 & 51 & 6 \\
\hline $10-19$ & 766 & 17 & 551 & 24 & 215 & 10 & 130 & 9 & 105 & 14 & 25 & 3 \\
\hline $20-29$ & 892 & 18 & 515 & 19 & 377 & 17 & 121 & 8 & 74 & 9 & 47 & 6 \\
\hline $30-39$ & 1022 & 20 & 612 & 23 & 410 & 18 & 124 & 7 & 62 & 7 & 62 & 7 \\
\hline $40-49$ & 990 & 32 & 518 & 32 & 472 & 31 & 182 & 11 & 80 & 11 & 102 & 12 \\
\hline $50-59$ & 1118 & 70 & 413 & 52 & 705 & 87 & 230 & 26 & 92 & 22 & 138 & 30 \\
\hline $60-69$ & 1400 & 136 & 446 & 93 & 954 & 173 & 446 & 72 & 117 & 43 & 329 & 96 \\
\hline $70-79$ & 2077 & 355 & 598 & 238 & 1479 & 444 & 959 & 234 & 292 & 166 & 667 & 286 \\
\hline $80-89$ & 2047 & 906 & 482 & 581 & 1565 & 1095 & 957 & 667 & 265 & 425 & 692 & 852 \\
\hline $90+$ & 638 & 1280 & 151 & 893 & 487 & 1478 & 315 & 1135 & 65 & 565 & 250 & 1540 \\
\hline
\end{tabular}

^Includes one case with unknown gender.

Note: Table includes 102881 (98\%) of 104902 total cases. Not shown are Native American (162), other (1054), and unknown (805).

Source: California Office of Statewide Health Planning \& Development, patient discharge records and California Department of Finance, 1970-96 Population Estimates, January 1998 
Table 2 Principal diagnosis of hospital admission rates (per 100 000) and 95\% confidence intervals (CI) for patients hospitalized for same level fall injuries, by sex, California residents, 1995-97

\begin{tabular}{|c|c|c|c|c|c|c|c|c|}
\hline & \multicolumn{2}{|c|}{ White } & \multicolumn{2}{|c|}{ Hispanic } & \multicolumn{2}{|l|}{ Black } & \multicolumn{2}{|c|}{ Asian/Pacific Islander } \\
\hline & Rate & $C I$ & Rate & $C I$ & Rate & $C I$ & Rate & $C I$ \\
\hline \multicolumn{9}{|l|}{ Females } \\
\hline Hip fracture & 71 & 69.2 to 72.3 & 33 & 30.8 to 36.1 & 28 & 24.3 to 31.8 & 26 & 23.4 to 29.5 \\
\hline All other fractures & 57 & 55.6 to 58.6 & 38 & 35.6 to 40.3 & 33 & 29.6 to 37.1 & 20 & 17.2 to 22.1 \\
\hline Superficial injury & 8 & 7.5 to 8.6 & 4 & 3.5 to 5.2 & 7 & 5.0 to 8.4 & 2 & 1.4 to 3.1 \\
\hline Circulatory problems & 6 & 5.6 to 6.4 & 4 & 3.3 to 5.2 & 6 & 4.2 to 7.5 & 4 & 2.5 to 4.8 \\
\hline Traumatic brain injury & 4 & 3.9 to 4.7 & 3 & 2.6 to 4.0 & 4 & 2.4 to 4.9 & 3 & 1.9 to 3.9 \\
\hline All other & 96 & 94.0 to 97.6 & 17 & 15.4 to 18.7 & 50 & 44.9 to 54.7 & 10 & 8.2 to 11.8 \\
\hline \multicolumn{9}{|l|}{ Males } \\
\hline Hip fracture & 36 & 34.7 to 37.6 & 17 & 14.7 to 19.2 & 20 & 16.5 to 24.4 & 11 & 8.7 to 13.0 \\
\hline All other fractures & 28 & 27.1 to 29.5 & 20 & 18.4 to 21.3 & 20 & 17.1 to 22.9 & 9 & 7.2 to 10.4 \\
\hline Superficial injury & 7 & 6.0 to 7.1 & 3 & 2.7 to 4.0 & 5 & 3.8 to 6.9 & 2 & 1.0 to 2.5 \\
\hline Circulatory problems & 6 & 5.7 to 6.9 & 4 & 3.4 to 5.6 & 5 & 3.1 to 6.8 & 3 & 1.8 to 4.1 \\
\hline Traumatic brain injury & 6 & 5.4 to 6.5 & 5 & 4.0 to 5.6 & 5 & 3.8 to 7.0 & 4 & 2.9 to 5.3 \\
\hline All other & 23 & 21.5 to 23.7 & 33 & 30.2 to 35.6 & 22 & 18.2 to 25.1 & 20 & 16.9 to 22.6 \\
\hline
\end{tabular}

Note: Data are age adjusted to the National Center for Health Statistics year 2000 US standard population.

Not shown on table are Native American (162), other (1054), and unknown (805).

Source: California Office of Statewide Health Planning \& Development, patient discharge records.

rates for whites were very high (161 for all ages), compared with blacks (64), Hispanics (43), and Asian/Pacific Islander (35) (all statistically significant at $\mathrm{p}<0.05$ ); and (3) women consistently had higher rates than men after age 50-59. Figure 1 vividly illustrates that older whites had distinctively high rates, despite statistically significant differences in rates among the other race/ethnic groups.

Most same level fall injuries $(70 \%)$ resulted in hospitalization because of a fracture. Table 2 shows significant differences in age adjusted admission rates for any fracture for both sexes. The largest race differential was for hip fracture, the predominant fracture, with the white rate about twice that of Hispanics and blacks and 3 times as large as the rate for Asians/Pacific Islanders. The ratio of female to male admission rates because of hip fracture was $1.4: 1$ for blacks and $2: 1$ for the other major race/ethnicity categories.

RACE/ETHNICITY AND OUTCOMES OF FALLS

Table 3 shows age adjusted disposition at discharge rates for same level fall injuries by race/ethnicity category. Although transfers to long term care and a routine discharge home were the major discharge destinations for all race/ethnicity categories, here, too, rates differed greatly by race/ethnicity. White females and males were transferred to long term nursing home care at a significantly higher rate, and Asian/Pacific Islanders at a significantly lower rate, than the other categories. This was also the pattern for a routine discharge home. However, within race/ethnicity categories, females (particularly whites and Hispanics) had the highest rates and were more at risk of being discharged to a long term care facility than males. But males, except whites, were significantly more likely to be discharged home than to long term care than females. Although the rate of males and females dying in hospital after being admitted because of same level fall injuries was low, whites of both sexes had significantly higher rates than their non-white counterparts.

Same level fall injuries constituted a large proportion of hospital charges billed for the treatment of injuries. For whites, same level falls amounted to nearly one fourth of the charges for all injuries (24\%), almost twice as high as the proportion for Asian/Pacific Islanders $(13 \%)$, and about three times as high as the proportion for blacks $(7 \%)$ and Hispanics (8\%) (data not shown). Falls, while consuming a minor proportion of charges for injuries among children and young adults, became a significant contributor after age 50 . By age 80 ,

Table 3 Disposition at discharge rates (per 100 000) and 95\% confidence intervals (CI) for patients hospitalized for same level fall injuries, by sex, California residents, 1995-97

\begin{tabular}{|c|c|c|c|c|c|c|c|c|}
\hline & \multicolumn{2}{|c|}{ White } & \multicolumn{2}{|c|}{ Hispanic } & \multicolumn{2}{|c|}{ Black } & \multicolumn{2}{|c|}{ Asian/Pacific Islander } \\
\hline & Rate & $C I$ & Rate & $C I$ & Rate & $C I$ & Rate & $C I$ \\
\hline \multicolumn{9}{|l|}{ Females } \\
\hline Long term care & 83 & 81.7 to 85.0 & 35 & 32.0 to 37.4 & 37 & 32.4 to 41.0 & 27 & 23.6 to 29.8 \\
\hline Routine & 54 & 52.6 to 55.5 & 46 & 43.7 to 48.8 & 41 & 36.8 to 44.9 & 22 & 19.8 to 24.8 \\
\hline Home health service & 17 & 16.2 to 17.8 & 10 & 8.8 to 11.6 & 11 & 8.3 to 12.7 & 8 & 6.1 to 9.3 \\
\hline Other transfers & 13 & 12.5 to 13.9 & 7 & 5.7 to 8.0 & 9 & 6.5 to 10.6 & 6 & 4.9 to 7.9 \\
\hline Died & 3 & 2.4 to 3.0 & 2 & 1.1 to 2.2 & 1 & 0.6 to 2.2 & 2 & 0.8 to 2.3 \\
\hline All other & 1 & 0.8 to 1.2 & 1 & 0.3 to 0.9 & 1 & 0.6 to 2.1 & $\star$ & NA \\
\hline \multicolumn{9}{|l|}{ Males } \\
\hline Long term care & 41 & 39.6 to 42.7 & 18 & 15.7 to 20.4 & 21 & 17.2 to 25.5 & 12 & 9.7 to 14.5 \\
\hline Routine & 42 & 40.7 to 43.6 & 35 & 32.6 to 36.6 & 40 & 35.8 to 44.2 & 22 & 19.8 to 24.8 \\
\hline Home health service & 9 & 8.1 to 9.5 & 4 & 3.4 to 5.5 & 5 & 3.4 to 7.1 & 3 & 1.9 to 4.1 \\
\hline Other transfers & 9 & 8.0 to 9.3 & 5 & 4.1 to 6.3 & 6 & 4.1 to 8.2 & 3 & 2.2 to 4.6 \\
\hline Died & 4 & 3.3 to 4.3 & 2 & 1.3 to 2.8 & 3 & 1.2 to 4.1 & 2 & 0.7 to 2.4 \\
\hline All other & 1 & 1.0 to 1.5 & 1 & 0.7 to 1.4 & 2 & 1.4 to 3.2 & 1 & 0.1 to 1.0 \\
\hline
\end{tabular}

«Less than 0.5 (0.3). NA = not applicable.

Note: Data are age adjusted to the National Center for Health Statistics year 2000 US standard population.

Not shown on table are Native American (162), other (1054), and unknown (805).

Source: California Office of Statewide Health Planning \& Development, patient discharge records. 
a majority of charges for injuries were attributed to same level falls. Patterns for the race/ethnicity groups (data not shown) were similar up to age 59. From age 60 and over, the percentage of fall related charges for whites rises greatly compared to the other race/ ethnicity groups.

\section{Discussion}

This is the first published population based study of hospitalized fall injuries comparing four major race/ethnic groups. The findings strongly confirm what other research had suggested - that whites have a distinctively high fall injury rate. ${ }^{13-29}$ To control somewhat for possible differences in behavior that might affect risk of falling, we limited our analysis to falls on the same level.

A main limitation of this study is our inability to study some known risk factors (for example, environmental hazards and medication use) that are not included in California hospital discharge records. Furthermore, hospital records for 1995-97 did not identify type of fall for 89841 (or $37 \%$ ) of all cases. To the degree that unidentified fall injuries include same level falls, we underestimate incidence and costs. Unidentified fall injuries have age and race/ ethnicity patterns similar to fall injuries on the same level.

Other research has documented strong differences in fall injury rates by age, sex, and race/ethnicity. Our study found that these differences appear to be independent. That is, rates within each of the four major race/ethnic groups have a distinctive age curve for males and females. Among older people, rates for white women are roughly twice that of women in other race/ethnic groups. Although not part of this analysis, we also found that older whites have the highest fall death rates of the major race/ethnic groups.

In exploring these race/ethnic differences, we found hip and leg fractures to be the most common principal diagnosis, particularly among whites. This pattern could implicate bone differences (osteoporosis) as an explanation for the race/ethnic differences we found. Some research certainly points in this direction. Nevitt et al found, as did we, that fractures result from falls most often in whites. ${ }^{13}$ Compared with blacks, whites have been found to have higher fracture rates in general, ${ }^{10} 133031$ which is consistent with a body of research showing that bone mass density is lower in whites. ${ }^{11}{ }^{32-34}$ All this suggests that the distinctive pattern we found for older whites may have its etiology in bone density, although other explanations, such as a greater tendency to fall or to report falling, cannot be ruled out. ${ }^{13}$ One possibility is that whites are more readily able to access medical services than non-whites, because whites have higher socioeconomic status. Using expected payer as a socioeconomic status surrogate, we found that non-whites were nearly four times as likely to have their hospitalization paid for by a public assistance program than whites $(28 \% v 5 \%)$.

\section{Implications for prevention}

This study certainly supports the notion that falls are worthy of a great deal of attention by public health professionals. Even limiting ourselves to falls on the same level, the rate, number, and costs of these injuries are extremely large. The proportion and number of people in the older age groups are projected to grow, exacerbating the strain on resources. ${ }^{35}$

Our study, and a recent one by Gill et al focusing on injury and non-injury falls, ${ }^{36}$ suggest that falls among older people are less a matter of environmental hazards than of physical factors, such as bone mass and physical condition. This would argue for fall prevention based on strategies such as osteoporosis prophylaxis, balance training, and other physical conditioning. Therefore, for public health policy, it is prudent to consider Gill and colleagues' recommendation to use sparse fall prevention resources to modify known intrinsic risk factors. ${ }^{36}$

The distinctive pattern of fall injuries and outcomes for whites requires a closer look at factors affecting this group. White rates are so raised that they become an attractive target for intervention. In our study, whites were only $29 \%$ of the population but accounted for over $53 \%$ of all same level fall injuries. Moreover, there is some evidence that prevention strategies may work differently among the race/ethnic groups. For example, research has found race differences in exercise preferences ${ }^{37}$ and in lactase deficiency and dietary intake of calcium from dairy products. ${ }^{38}$ There may be other systematic differences between whites and other race/ethnic groups that need greater elucidation.

The California Department of Health Services supported this research.

1 Davis JW, Ross PD, Nevitt MC, et al. Incidence rates of falls among Japanese men and women living in Hawaii. $\mathcal{F}$ Clin Epidemiol 1997;50:589-94

2 Jacobsen SJ, Goldberg J, Miles TP, et al. Seasonal variation in the incidence of hip fracture among white persons aged 65 years and older in the United States. Am 7 Epidemiol 1991;133:996-1004.

3 Wolinsky FD, Fitzgerald JF. The risk of hip fracture among noninstitutionalized older adults. F Gerontol 1994;49:S165-

4 Felson DT, Kiel DP, Anderson JJ, et al. Alcohol consumption and hip fractures: the Framingham study. Am $\mathcal{F}$ Epidemiol 1988;128:1102-10.

5 Rodriguez JG, Sattin RW, Waxweiler RJ. Incidence of hip fractures, United States, 1970-83. Am f Prev Med 1989;5: 175-81.

6 Visentin P, Ciravegna R, Uscello L, et al. Site-specific relative risk of fractures in the institutionalized elderly. Gerontology 1995;41:273-9.

7 Hemenway D, Feskanich D, Colditz GA. Body height and hip fracture: a cohort study of 90,000 women. Int $\mathcal{F}$ Epidemiol 1995;24:783-6.

8 Birge SJ. Osteoporosis and hip fracture. Clin Geriatr Med 1993;9:69-86.

9 Lauritzen JB, McNair PA, Lund B. Risk factors for hip fractures. A review. Dan Med Bull 1993;40:479-85

10 Griffin MR, Ray WA, Fought RL, et al. Black-white differences in fracture rates. Am F Epidemiol 1992;136: 1378-85.

1 Nevitt MC. Epidemiology of osteoporosis. Rheum Dis Clin North Am 1994;20:535-59.

12 Grisso JA, Wishner AR, Schwarz DF, et al. A populationbased study of injuries in inner-city women. Am $\mathcal{F}$ Epidemiol 1991;134:59-68.

13 Nevitt MC, Cummings SR, Kidd S, et al. Risk factors for recurrent nonsyncopal falls. $\mathcal{F A M A}$ 1989;261:2663-8.

14 Sattin RW, Huber DAL, DeVito CA, et al. The incidence of fall injury events among the elderly in a defined population. Am f Epidemiol 1990;131:1028-37.

15 Sattin RW. Falls among older persons: a public health perspective. Annu Rev Public Health 1992:13:489-508. 
16 Wofford JL, Heuser MD, Moran WP, et al. Community surveillance of falls among the elderly using computerized EMS transport data. Am f Emerg Med 1994;12:433-7.

17 Sattin RW, Rodriguez JG, Devito CA, et al. The epidemiology of fall-related injuries among older persons. In Weindruch R, Hadley EC, Ory MG, eds. Reducing frailty and falls in older persons. Springfield, IL: Charles C Thomas, 1991.

18 Alexander BH, Rivara FP, Wolf ME. The cost and frequency of hospitalization for fall-related injuries in older adults. Am F Public Health 1992;82:1020-3.

19 Kannus P, Palvanen M, Niemi S, et al. Increasing number and incidence of fall-induced severe head injuries in older adults. Am f Epidemiol 1999;149:143-50.

20 Runge J. the cost of injury. Emerg Med Clin North Am 1993 11:241-53.

21 Schwarz DF, Grisso JA, Miles CG, et al. A longitudinal study of injury morbidity in an African-American populastudy of injury morbidity in an

22 Grisso JA, Schwarz DF, Wolfson V, et al. The impact of falls in an inner-city elderly African-American population. $7 \mathrm{Am}$ Geriatr Soc 1992:40:673-8.

23 Schwartz AV, Villa ML, Prill M, et al. Falls in older Mexican-American women. I Am Geriatr Soc 1999;47: Mexican-A

24 Anderson RN, Rosenberg HM. Age standardization of death rates: implementation of the year 2000 standard. National vita statistics reports; vol 47 No 3. Hyattsville, MD: National Center for Health Statistics, 1998.

25 National Osteoporosis Foundation. 1996 and 2015 Osteoporosis prevalence figures. State by state report. National Osteoporosis Foundation, January, 1997.

26 Looker AC, Orwoll ES, Johnston CC, et al. Prevalence of low femoral bone density in older US adults from NHANES III. $\mathcal{\exists}$ Bone Miner Res 1997;12:1761-8.

27 Melton LJ. How many women have osteoporosis now? $\mathcal{f}$ Bone Miner Res 1995;10:175-7.
28 Zimmerman SI, Girman CJ, Buie VC, et al. The prevalence of osteoporosis in nursing home residents. Osteoporos Int of osteoporosis

29 Aharonoff GB, Dennis MG, Elshinawy A, et al. Circumstances of falls causing hip fractures in the elderly. Clinical Orthopaedics and Related Research 1998;348:10-14.

30 Current Estimates from the National Health Interview Survey, 1995. Hyattsville, MD: National Center for Health Statistics Series 10, \#199, 1998.

31 Bohannon AD, Hanlon JT, Landerman R, et al. Association of race and other potential risk factors with nonvertebral fractures in community-dwelling elderly women. Am f Epidemiol 1999;149:1002-9.

32 Cauley JA, Danielson ME, Gregg EW, et al. Calcaneal ultrasound attenuation in older African-American and Caucasian women. Osteoporosis Int 1997;7:100-4.

33 Wright NM, Renault J, Willi S, et al. Greater secretion of growth hormone in black than in white men: possible factor in greater bone mineral density-a clinical research center study. F Clin Endocrinol 1995;80:2291-7.

34 Bell NH, Gordon L, Stevens J, et al. Demonstration that bone mineral density of the lumbar spine, trochanter, and femoral neck is higher in black than in white young men. Calcif Tissue Int 1995;56:11-13

35 National Center for Injury Prevention and Control. Unintentional fall deaths and rates per 100,000 www.cdc.gov/ncipc/osp/us9693/Ufall.htm.

36 Gill TM, Williams CS, Tinetti ME. Environmental hazards and the risk of nonsyncopal falls in the homes of community-living older persons. Medical Care 2000;38: $1174-83$

37 Miller DK, Morrison MJ, Blair SD, et al. Predilection for railty remedial strategies among black and white seniors. South Med F 1998;91:375-80.

38 Bertron P, Mills M. Racial bias in federal nutrition policy. Part 1: the public health implications of variations in lactase persistence. $\mathcal{F}$ Nat Med Assoc 1999;91:151-7.

Woman's bra stops nail shot from lawnmower

Michigan resident, Dana Colwell, had more than an uplifting experience with her bust-enhancing bra last June. She considers it a real lifesaver. While cutting her grass, the 31 year old was hit in the chest by a 1.5 inch nail that shot out from under her mower and punctured her right breast. Doctors say the injury would have been far worse had it not been for extra padding in Colwell's "liquid-curved" bra (Detroit Free Press, June 2001).

\section{This is what makes us Australian}

In case you wondered why Australians have a reputation as they do, read on:

- Three people die each year testing if a $9 \mathrm{~V}$ battery works on their tongue.

- 142 people were injured in 1998 by not removing all the pins from new shirts.

- 58 people are injured each year by using sharp knives instead of screwdrivers.

- 31 people have died since 1996 by watering their Christmas tree while the fairy lights were plugged in.

- 19 people have died in the last three years by eating Christmas decorations they believed were chocolate.

- Hospitals reported four broken arms last year after cracker pulling incidents.

- 101 people since 1997 have had to have broken parts of plastic toys pulled out of the soles of their feet.

- 18 people had serious burns in 1998 trying on a new jumper with a lit cigarette in their mouth.

- A massive 543 people were admitted to casualty in the last two years after opening bottles of beer with their teeth or eye socket.

- Five people were injured last year in accidents involving out of control Scalextric cars.

- And finally, eight people cracked their skull in 1997 after falling asleep (passing out) while throwing up into the toilet.

(Reputedly from the Australian Bureau of Statistics, via Jan Shield) 